\title{
THE SUITABILITY OF THE FORCE PLATE TO EVALUATE THE STABILITY DURING QUIET STANDING AND ANALYZING THE EFFECTS OF SHOES, GENDER AND AGE ON THE STANDING STABILITY
}

\author{
Journal website at; \\ http://mrtbjournal.org/index.php/njmr/issue/current/showToc \\ MTKARIMI \\ Bioengineering Unit, University of Strathclyde, Glasgow UK., \\ Correspondence to: MT Karimi \\ mohammad.karimi@strath.ac.uk
}

\begin{abstract}
SUMMARY
Background: Stability during standing is achieved by a complex process which is influenced by the ageing process. Using force plate is an acceptable method in order to evaluate stability. There is a number of parameters which can be used to evaluate the stability in quiet standing; however, the most common ones are: the excursion of Centre Of Pressure (COP), the mean amplitude and the standard deviation of the COP sway and the forces applied on the force plate. Unfortunately there is no standard way to analyze the standing stability with force plate or to select the subjects.
\end{abstract}

Objective: The main aims of this research were to measure the stability parameters of normal subjects according to a standard method and to evaluate the effects of wearing shoes, age and gender of the participants on the standing stability. The suitability of the force plate to check the difference between stability parameters during various standing conditions was also evaluated in this research project.

Methods: A group of 35 normal subjects, 10 females and 25 males, from the staff and students of Bioengineering Unit of University of Strathclyde were recruited and asked to stand on the force plate for one minute. They were selected according to their age and their health conditions. Specific tests were repeated 5 times for each subject. The difference between the mean values of the stability parameters was tested by using student $\mathrm{T}$ test and paired T test.
Results: The results of this study showed that shoes can influence the standing stability. Moreover, the force plate is quite sensitive and thus can show the effects of aging on standing stability.

Conclusion: Using parameters based on the COP sway can represent stability better than those parameters based on the forces applied on the force plate.

\section{KEYWORDS: Force plate, COPsway, stability}

\section{INTRODUCTION}

Stability during standing is achieved by a complex process that involves coordination activities of multiple sensory and motor components. In normal subjects, stability is achieved by coordinative motions that occur in the ankle, knee and hip joints and are done by muscles around theses joints (Jacobson et al, 1993). Some strategies such as head movement strategy, trunk strategy, hip, knee and ankle strategies can be used in order to maintain stability. However, in patients it can be enhanced by using external support like an orthosis, that restricts the unnecessary motion of the paralyzed joints during standing (Jacobson et al, 1993).

There are two different methods that are used exclusively to check the stability during quiet standing. The first method was developed by Rowery at the beginning of the nineteenth century and was based on body sway under opened and closed eyes (Jacobson et al, 1993). The difference in body sway during standing with opened and closed eyes is represented by the 
functional performance of the somatosensory system.

The second method is to check stability when an unexpected distribution force is applied on the subjects during standing (Jacobson et al, 1993). The first method is a common method and is used to evaluate the amount of stability during quiet standing and while doing hand tasks. To assess the stability the location of the COP is checked during a period of time. There are a lot of different parameters that have been used to represent the stability, these include:

a) The COP path length (O'Connell et al, 1998, Middleton et al, 1999)

b) The COP excursion (O'Connell et al, 1998, Raymakers et al, 2005)

c) Average speed of the COP change (Lafond et al, 2004)

d) Mean amplitude of the COP sway (Lafond et al, 2004)

e) Standard deviation of the force applied on the force plate (Le Clair and Riach, 1996)

f) Standard deviation of the COP sway (Le Clair and Riach, 1996)

g) Hip joint motion in standing position (Kagawa et al, 2006)

For handicapped subjects the amount of force applied on the crutch is another parameter which can be used to evaluate standing stability. This parameter was used by some researchers to measure the stability of the Spinal Cord Injury (SCI) subjects during standing with different orthoses (Baardman et al, 1997).

The reliability of the above mentioned parameters depends not only on the accuracy of the instrument but also on the procedure that is used to analyze stability. The repeatability and validity of these parameters depends on the durations of the test and the number of trials carried out (Doyle et al, 2005, Swanenburg et al, 2008, Santos et al, 2008). However, there is not a standard way to do a stability test. The condition of the subject during the test, type of wear (the heel height of the shoes), time of data collection, numbers of trials, frequency of collecting data and filtering procedure influence the final results. Samson and Crowe (1996) conducted a research to check the reliability of the force plate to measure stability. They found that there is a high level of variability when the subjects were retested on different days. They concluded that there is not a standard method for doing the stability test, some researchers did not ask the subjects to remove their shoes, while others asked that shoes and socks to be removed.

In the study of Goldie et al (1989), 28 normal subjects (14 females and 14 males) participated and asked to stand on a force plate in different positions with their eyes opened and closed. The result of this study showed that force measurement is more consistent for discrimination between different levels of stance difficulty. Moreover, the force plate was used to check the effect of the Anterior Cruciate
Ligament (ACL) on the standing stability.

The reliability and validity of the mentioned parameters was measured by different researchers. It was found that these parameters have acceptable reliability if 5 trials were collected from every subject and for at least one minute (Santos et al, 2008).

As can be seen from the literature there is no standard way to conduct the stability test with the force plate. In some researches both genders were used as a control group to check the difference between patients and normal subjects. However, some factors such as gender, type of foot wear and age may influence the stability. The aims of this research were:

a) To give the mean values of the stability parameters that were measured according to a standard method

b) To check the effect of foot wear on standing stability

c) To check the effect of aging on standing stability

d) To analyze the difference in stability between genders

\section{MATERIALSANDMETHODS}

Equipment: A Kistler force plate instrumented with piezoelectric force transducers was used to measure the centre of pressure which is considered to be a good approximation of sway. Sway during standing is defined by movements of Centre Of Gravity (COG) in a horizontal plane (Maki et al, 1987). These movements are due to small deviations of the vertical ground reaction vector. Many researchers have studied sway by measuring the COP on the force platform (Cybulski and Jaeger, 1986, Murray et al, 1975).

The force plate and the amplifier associated with it produce six voltage outputs that represents the mechanical inputs in:, which are the forces and moments applied on $\mathrm{X}, \mathrm{Y}$, and $\mathrm{Z}$ axes. The locations of the COP can be determined according to the following equations (Barnett, 1990, Geurts et al, 1993):

Whereby 0.057 metre is the thickness of the force plate.

Subjects: Table 1 shows the number and characteristics of the subjects participated in different parts of this research. The subjects were recruited from the students and staff members of Bioengineering Unit of University of Strathclyde. They reported to have no musculoskeletal disorder, neurological illness, degenerative conditions or any diseases that would interface with their normal balance. In the first part of the research the difference between the stability parameters of the male and female participants was evaluated. In the second part the effect of the shoe on stability was evaluated, moreover the stability of a group of normal subjects was measured in the third part of this research. The main reason for undertaking the third part of this research was to measure the stability of a group of normal subjects according to a standard way which can be used as a data base in other research projects. 
Table 1: The number and characteristics of the subjects that participated in this research

\begin{tabular}{|c|c|c|c|c|c|c|}
\hline \multicolumn{3}{|c|}{ participants numberAge } & \multirow{2}{*}{$\begin{array}{l}\text { Height } \\
\pm 3.5\end{array}$} & \multirow{2}{*}{$\begin{array}{l}\text { Weight } \\
1.8 \\
\pm 0.06\end{array}$} & \multicolumn{2}{|c|}{$\begin{array}{l}\text { Part of the } \\
\text { research }\end{array}$} \\
\hline Males & 10 & 27.6 & & & $\begin{array}{l}76.2 \\
\pm 8\end{array}$ & First \\
\hline Females & 10 & 27.7 & \pm 2.7 & $\begin{array}{l}1.65 \\
\pm 0.06\end{array}$ & $\begin{array}{l}68 \\
\pm 11.8\end{array}$ & \\
\hline Males & 10 & 30.2 & \pm 8.4 & $\begin{array}{l}1.74 \\
\pm 0.05\end{array}$ & $\begin{array}{l}76.9 \\
\pm 8.4\end{array}$ & Second \\
\hline Males & 25 & 34.4 & \pm 13 & $\begin{array}{l}1.78 \\
\pm 0.07 \\
\end{array}$ & $\begin{array}{l}82.8 \\
\pm 12 \\
\end{array}$ & Third \\
\hline
\end{tabular}

Parameters: The parameters which were used in this research included:

a) Amplitude of anteroposterior COP sway (AAP)

b) Amplitude of mediolateral COP sway (AML)

c) Mean amplitude of anteroposterior COP sway (MAAP)

d) Mean amplitude of mediolateral COP sway (MAML)

e) Standard deviation of the force in anteroposterior direction (SFx)

f) Standard deviation of the force in mediolateral direction (SFy)

g) Standard deviation of the COP sway in anteroposterior direction (SAP)

h) Standard deviation of the COP sway in mediolateral direction (SML)

Procedure: The accuracy of the force plate according to the manufacturer's manual is high and the error of the system is less than 1\% (Hall et al, 1996). However, to maintain a guarantee of the output quality some tests were carried out to evaluate the accuracy of the data for shear loads both in mediolateral and anteroposterior directions and also for vertical loads. The results of force plate calibration showed that the errors of the system was not high, however it was more than supposed to be ( between 1 and $2 \%$ ).

In the next stage subjects were instructed about the procedure and instruments. Then their weight and their height were measured and recorded. The subjects were asked to stand on the force plate; they were instructed to look straight ahead, with their head erect and their arms at their sides in a comfortable position. The tests were recorded for one minute and were repeated 5 times for each subject (Santos et al, 2008). Analogue signals were sampled at a frequency of $120 \mathrm{~Hz}$ with an analogue to digital convertor and were stored on a computer. The signals of the force plate were filtered with a Butterworth low-pass filter at $10 \mathrm{~Hz}$ (Santos et al, 2008, Lafond et al, 2004). The first and last 15 seconds of the data were deleted and only 30 seconds of the data were used for the final analysis. The 30 seconds of the data was used to show the absolute sway of the COP. The first and last 15 seconds of the data were deleted as the subject may have some small motions during the first part and have some muscle fatigue at the last part of data collection period. For the second part of the test the subjects were asked to remove their shoes and socks and the same procedure was used.

\section{RESULTS}

Figure 1 shows the excursion of COP in the mediolateral and anteroposterior planes. The mean values of the stability parameters of the females and males are shown in table 2 . As can be seen, there was a difference between the mean values of the stability parameters between genders, however, the difference was not significant.

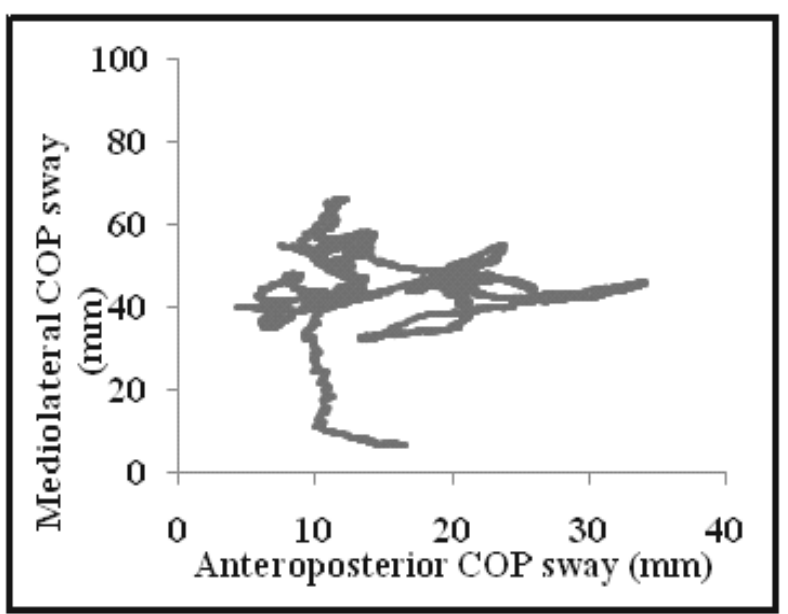

Figure 1: The excursion of COP in the mediolateral and anteroposterior planes (from one subject)

Table 2: The mean values of the stability parameters of males and females

\begin{tabular}{lll}
\hline Parameters & Males & Females \\
\hline MAP $(\mathrm{mm})$ & $4.3 \pm 1.45$ & $3.53 \pm 1.32$ \\
MML (mm) & $1.77 \pm 0.5$ & $2.25 \pm 1.15$ \\
SFx (N) & $0.995 \pm 0.42$ & $0.7 \pm 0.27$ \\
SFy (N) & $0.548 \pm 0.176$ & $0.79 \pm 0.9$ \\
SAP (mm) & $5.31 \pm 1.66$ & $4.36 \pm 1.61$ \\
SML (mm) & $2.27 \pm 0.65$ & $2.76 \pm 1.33$ \\
AAP (mm) & $27.57 \pm 4$ & $20.51 \pm 6.7$ \\
AML (mm) & $12.43 \pm 3.6$ & $13.76 \pm 5.67$ \\
\hline
\end{tabular}

The mean values of the stability parameters during standing with and without shoes are shown in table 3 . Although the stability of the participants in standing without shoes was better than that with shoes, the difference was not significant. The difference between the stability parameters of females and males was evaluated by using student $\mathrm{T}$ test. The significant point (á) was 0.05 for all parameters. The difference between the mean values of the stability parameters in standing with and without shoes was analyzed by using paired $\mathrm{T}$ test.

The stability parameters of the male participants are shown in table 4 . The results of the Pearson correlation test showed that there was a significant correlation 
between the age of the participants and the amount of COP excursions in both planes. The Pearson correlation values were 0.446 and 0.394 for the anteroposterior and mediolateral stability, respectively.

Table 3: The mean values of the stability parameters during standing with and without shoes

\begin{tabular}{lll}
\hline Parameters & With shoes & Without shoes \\
\hline MAP (mm) & $4.77 \pm 1.17$ & $4.3 \pm 0.75$ \\
MML (mm) & $1.92 \pm 0.7$ & $1.42 \pm 0.7$ \\
SFx (N) & $0.767 \pm 0.27$ & $0.71 \pm 0.24$ \\
SFy (N) & $0.428 \pm 0.12$ & $0.395 \pm 0.1$ \\
SAP (mm) & $5.75 \pm 2.1$ & $5.3 \pm 0.84$ \\
SML (mm) & $2.1 \pm 0.81$ & $1.78 \pm 0.8$ \\
AAP (mm) & $25 \pm 6.92$ & $22.5 \pm 5.25$ \\
AML (mm) & $10.4 \pm 3.5$ & $9.3 \pm 2.84$ \\
\hline
\end{tabular}

Table 4: The mean values of the stability parameters of the male participants

\begin{tabular}{ll}
\hline Parameters & Mean values \\
\hline MAP (mm) & $4.33 \pm 1.7$ \\
MML (mm) & $2.2 \pm 1.05$ \\
SFx $(\mathrm{N})$ & $1.08 \pm 0.55$ \\
SFy $(\mathrm{N})$ & $0.62 \pm 0.32$ \\
SAP $(\mathrm{mm})$ & $5.46 \pm 2.15$ \\
SML (mm) & $2.76 \pm 1.5$ \\
AAP (mm) & $25.66 \pm 11.3$ \\
A ML (mm) & $15.22 \pm 9.02$
\end{tabular}

\section{DISCUSSION}

Difference between the stability of the males and females: The results of the stability parameters showed that the stability of the females in the anteroposterior direction is better than males. However, the stability of the males in the mediolateral direction is better than that of the females. The reason may be related to anthropometrical difference between genders. So using both genders in a control group to compare the difference in stability without gender matching is not acceptable.

There is no consensus in the literature regarding gender differences in stability. The results of the research carried out by Goldie et al (1989), which was done on 14 female and 14 males participants showed that the difference between genders regarding stability was not significant. However, it was assumed that the difference between body height of men and women contributes to the poorer stability of men compared to women (Kinney LaPier et al, 1997). Ekhdahl et al (1989) showed that females are more stable than males. In contrast Overstall found that men are more stable than women in standing (Overstall et al, 1977). Other researchers found no difference between the stability between females and males (Black et al, 1982, Kinney LaPier et al, 1997).

The difference found in the current research may be related to the procedure used to carry out the stability test or to age difference amongst the participants. It worths to be noted that the age of the participants in different studies varies, so any comparison of the results concerning the effect of gender should be made with caution.

Effects of age on stability: The results of this research showed that the amount of stability especially in the mediolateral direction decreased with ageing. This may be related to the effects of ageing on the functions of the systems which are responsible to maintain and control standing stability. It was found that visual, vestibular and somatosensory functions diminish with aging (Jacobson et al, 1993). Loss of muscle strength and decreased function of the joint mechano- receptors may be some other factors which influence the stability.

Effects of the shoe on stability: Although wearing shoes influences stability, the difference between the standing conditions is not significant. This insignificance decrease in stability when using shoes may be related to the effects of heel height on the alignment of the lower limb during standing.

\section{CONCLUSION}

The results of this research showed that stability tests with a force plate must be performed according to a standard procedure. The duration of the test must be one minute and it is necessary to be repeated for 5 times. It was shown by Santos et al (2008) that the COP sway has good reliability and repeatability if the tests were done for one minute and were repeated for 5 times. The results of this research also showed that using the COP sway and especially using the amplitude of the COP seems to be more sensitive method than using force parameters. As it was shown, the only standing parameters that have a significant correlation with age were the COP excursions. It was shown that using the force plate is a good way to measure stability. The effects of aging on stability can be defined by using a force plate; however, the test must be carried out according to a standard procedure. It is recommended that the age of the participants, type of shoes and gender should be considered when the difference between the stability of different groups is compared. The data of stability parameters collected in this research can be used as the base for further research.

\section{ACKNOWLEDGMENT}

The author wishes to thank all subjects who kindly participated in this research. This project was supported by a grant devoted to author by Iranian Ministry of education and Medical sciences.

\section{REFERENCES}

- Baardman, G, Ijzerman, MJ, Hermens, HJ, Veltink, PH, Boom, HB, Zilvold, G (1997) The influence of the reciprocal hip joint link in the Advanced Reciprocating Gait Orthosis on standing performance in paraplegia. Prosthetics and Orthotics International 21: 210-21. 
- Barnett, RW (1990) Paraplegic standing and reciprocal gait using a floor reaction hybrid F.E.S orthosis, PhD Thesis, University of Strathclyde, Glasgow.

- Black, FO, Wall, C, 3rd, Rockette, HE, Jr., Kitch, R (1982) Normal subject postural sway during the Romberg test. American journal of Otolaryngology 3: 309-18.

- Cybulski, GR, Jaeger, RJ (1986) Standing performance of persons with paraplegia. Archives of Physical Medicine and Rehabilitation 67: 103-8.

- Doyle, TI, Newton, RU, Burnett, AF (2005) Reliability of traditional and fractal dimension measures of quiet stance center of pressure in young, healthy people. Archives of Physical Medicine and Rehabilitation 86: 2034-40.

- Ekdahl, C, Andersson, SI (1989) Standing balance in rheumatoid arthritis. A comparative study with healthy subjects. Scandinavian journal of Rheumatology 18: 33-42.

- Geurts, AC, Nienhuis, B, Mulder, TW (1993) Intrasubject variability of selected force-platform parameters in the quantification of postural control. Archives of Physical Medicine and Rehabilitation 74: 1144-1450.

- Goldie, PA, Bach, TM, Evans, OM (1989) Force Platform measures for Evaluation postural control: Reliability and Validity. Archives of Physical Medicine and Rehabilitation 70: $510-517$.

- Hall, MG, Fleming, HE, Dolan, MJ, Millbank, SF, Paul, JP (1996) Static in situ calibration of force plates. Journal of Biomechanics 29: 659-665.

- Jacobson, GP, Newman, CW, Kartush, JM (1993) Handbook of balance function testing, Mosby Year Book.

- Kagawa, T, Fukuda, H, Uno, Y (2006) Stability analysis of paraplegic standing while wearing an orthosis. Medical and Biological Engineering \& Computing 44: 907-917.

- Kinney LaPier, TL, Liddle, S, Bain, C (1997) A comparison of static and dynamic standing balance in older men versus women. Physiotherapy Canada 49: 207-213.

- Lafond, DF, Corriveau, H, Hebert, R, Prince, F (2004) Intrasession reliability of center of pressure measures of postural steadiness in healthy elderly people. Archives of Physical Medicine and Rehabilitation 85: 896-901.

- Le Clair, K, Riach, C (1996) Postural stability measures: what to measure and for how long. Clinical Biomechanics 11: 176-178.

- Maki, BE, Holliday, PJ, Fernie, GR (1987) A posture control model and balance test for the prediction of relative postural stability. IEEE Transactions on Biomedical Engineering 34: 797-810.

- Middleton, JW, Sinclair, PJ, Smith, RM, Davis, GM (1999) Postural control during stance in paraplegia: effects of medially linked versus unlinked knee-ankle-foot orthoses. Archives of Physical Medicine and Rehabilitation 80: 155865.

- Murray, MP, Seireg, AA, Sepic, SB (1975) Normal postural stability and steadiness: quantitative assessment. The Journal of Bone and Joint Surgery 57: 510-6.

- O'Connell, M, George, K, Stock, D (1998) Postural sway and balance testing: a comparison of normal and anterior cruciate ligament deficient knees. Gait \& Posture 8: 136142.

- Overstall, PW, Exton-Smith, AN, Imms, FJ, Johnson, AL (1977) Falls in the elderly related to postural imbalance. BMJ 26: 261-4.

- Raymakers, JA, Samson, MM, Verhaar, HJJ (2005) The assessment of body sway and the choice of the stability parameter(s). Gait \& Posture 21: 48-58.

- Samson, M, Crowe, A (1996) Intra-subject inconsistencies in quantitative assessments of body sway. Gait \& Posture 4: 252-257.

- Santos, BR, Delisle, A, C., L, Plamondon, A, Imbeau, D (2008) Reliability of centre of pressure summary measures of postural steadiness in healthy young adults. Gait \& Posture 27: 408-15.

- Swanenburg, J, de Bruin, ED, Favero, K, Uebelhart, D, Mulder, T (2008) The reliability of postural balance measures in single and dual tasking in elderly fallers and non-fallers. BMC Musculoskeletal Disorders 9: 159-162. 